Asian Spine Journal

Vol. 3, No. 1, pp 35 38, 2009

\title{
Multiple Levels of Lumbar Spondylolysis - A Case Report -
}

\author{
Kwang-Hwan Park, Joong-Won Ha, Hak-Sun Kim, Eun-Su Moon, Seong-Hwan Moon, \\ Hwan-Mo Lee, Ho-Joong Kim, Ju-Young Kim
}

Department of Orthopedic Surgery, Yonsei University College of Medicine, Seoul, Korea

\begin{abstract}
We report here on an unusual case of multiple levels of asymmetric lumbar spondylolysis in a 19-year-old woman. The patient had severe low back pain of increasing intensity with lumbar instability, which was evident on the dynamic radiographs. MRI demonstrated the presence of abnormalities and the three dimensional CT scan revealed asymmetric complete spondylolysis at the left L2, L3 and L4 levels and the right L1, L2 and L3 levels. This case was treated surgically by poste rior and posterolateral fusion at L2-3-4 with intersegmental fixation using pedicle screws and an auto iliac bone graft. The patient was relieved of her low back pain after the surgery.
\end{abstract}

Key Words: Lower back pain, Multiple spondylolysis, Fusion

\section{Introduction}

Lumbar spondylolysis is commonly seen at the fourth and fifth lumbar vertebrae. Spondylolysis at the fourth and fifth lumbar vertebrae accounts for more than $95 \%$ of the total cases of spondylolysis ${ }^{1}$. However, multiple lumbar spondylolysis is an unusual and relatively rare finding. The incidence of multiple lumbar spondylolysis appears to vary between $1.2 \%{ }^{2,3}$ to $5.6 \%{ }^{4}$. Al-Sebai and Al-Khawashki ${ }^{5}$ have previously had reported on a rare case of bilateral three level lumbar spondylolysis that was associated with one level spondylolisthesis. We report here on a rare case of asymmetric four level lumbar spondylolysis.

\section{Case Report}

A 19-year-old Korean woman visited our out-patient clinic for severe back pain that had developed spontaneously. The patient was a student at the college of physical educa- tion. The patient initially noticed a kyphosis in the lumbar area around three years ago. However, since it was not associated with any significant disability or pain, she was treated conservatively at that time. Yet after a routine exercise program for entering the college of physical education, she developed low back pain for which she was prescribed oral medication. However, the back pain did not improve with the oral analgesics and it started to increase in intensity.

At the time of presentation at our outpatient clinic, a lumbar kyphosis was noticed in the standing position. Grossly, the kyhosis and instability of the lower back were moderate to severe. The kyphosis was found to be flexible because the kyphosis could be corrected when the low back area was pushed anteriorly by the surgeon's hands. She had severe lower back pain. The visual analogue score (VAS) was 8 points. The patient also showed generalized ligamentous laxity. There were no neurological signs or symptoms. The initial radiographs showed a hypoplastic change in the spinous processes and lamina of the lumbar vertebrae, multiple spondylolysis and lumbar instability (Fig. 1). The magnetic resonance imaging (MRI) demonstrated the presence of

Received Dec 22, 2008; 1st revised Feb 14, 2009; 2nd revised Feb 25, 2009; accepted Feb 26, 2009

Corresponding author: Eun-Su Moon, MD

Department of Orthopedic Surgery, Gangnam Severance Hospital, Yonsei University College of Medicine

612 Eonjuro, Gangnam-gu, Seoul, 135-720, Korea

Tel: +82-2-2019-3418, Fax: +82-2-573-5393, E-mail: mes1007@yuhs.ac

Copyright (C) 2009 by Korean Society of Spine Surgery

This is an Open Access article distributed under the terms of the Creative Commons Attribution Non-Commercial License (http://creativecommons.org/licenses/by-nc/3.0) which permits unrestricted non-commercial use, distribution, and reproduction in any medium, provided the original work is properly cited. 

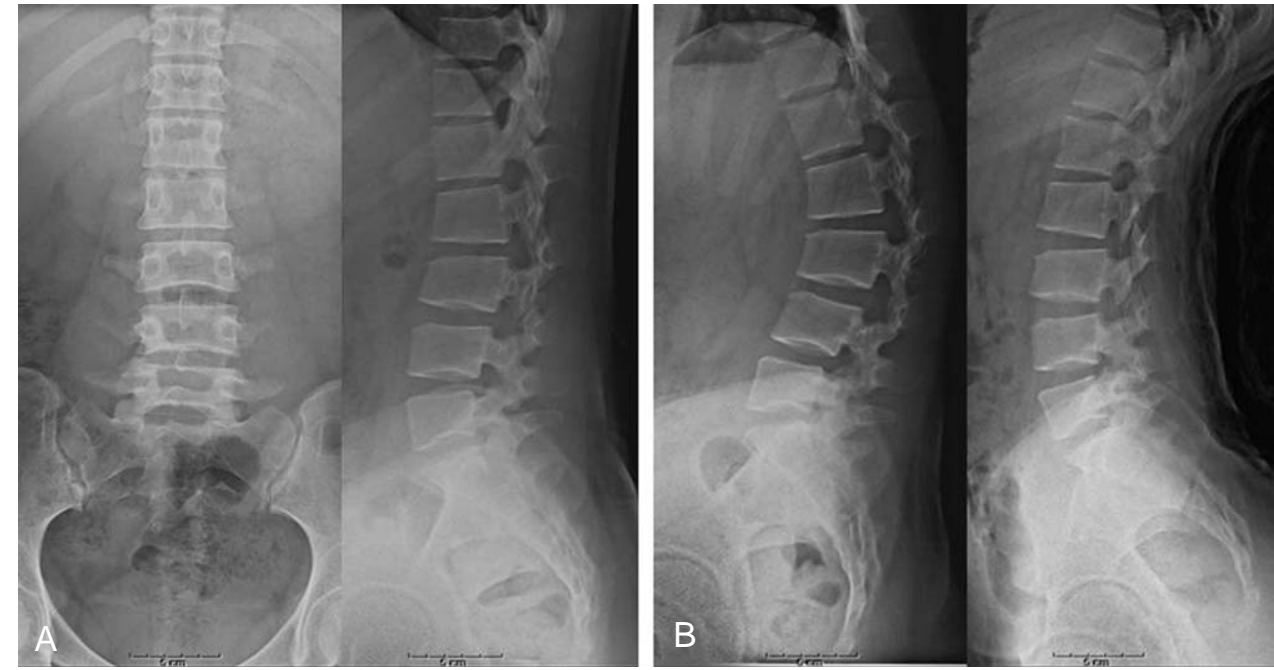

Fig. 1. (A) Anteroposterior and lateral radiography - Mild kyphosis and L2,3 spondylolysis are seen at lateral radiography. (B) Lateral radiography of flexion and extension view - Lumbar instability is noted.

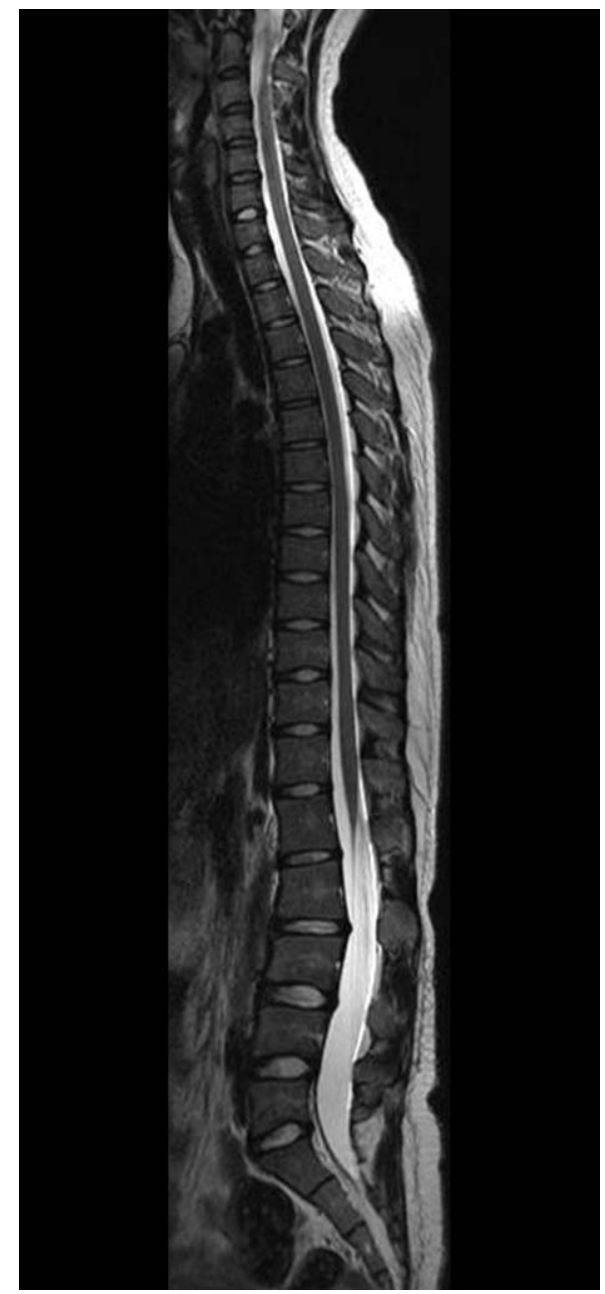

Fig. 2. Sagittal T2-weighted MR scan of whole spine demonstrating mild kyphosis. No evidence of abnormality of disc and soft tissue. kyphosis of the upper lumbar spine and multiple levels of spondylolysis (Fig. 2). A three dimensional computed tomography (CT) scan was performed to get a complete picture of the lesions. The $\mathrm{CT}$ scan showed asymmetric complete spondylolysis at the left L2/3/4 levels (Fig. 3A) and the right L1/2/3 levels (Fig. 3B). The activities of daily living were severely limited, and so a surgical operation was performed. Obvious instability of the L2/3/4 segments was noted intraoperatively. The pars interarticularis of L2/3/4 were dystrophic, so defect repair was impossible. Posterior lumbar interbody fusion was not chosen. Because the patient had no neurologic symptoms, we did not need to open the neural canal, and laminectomy was not done. A two level posterior and posterolateral fusion was carried out at the L2/3/4 levels with intersegmental fixation by using pedicle screws and an auto iliac bone graft (Fig. 4A). The harvest site of the auto iliac bone was located beneath the Bikini line. The preoperative segmental angle of the operated levels was 15 degrees of kyphosis while the postoperative angle for the fused segment was 8 degrees of lordosis. After operation, the patient's lower back pain was much relieved and the VAS was 4 points. The postoperative 1 year follow-up of the patient showed no neurological deficit, no lumbar instability and no hardware failure (Fig. 4B). There was a very good improvement of her symptoms and she was satisfied with the cosmetic result. The patient was completely relieved of lower back pain after the surgery, and the VAS was 2 points. 

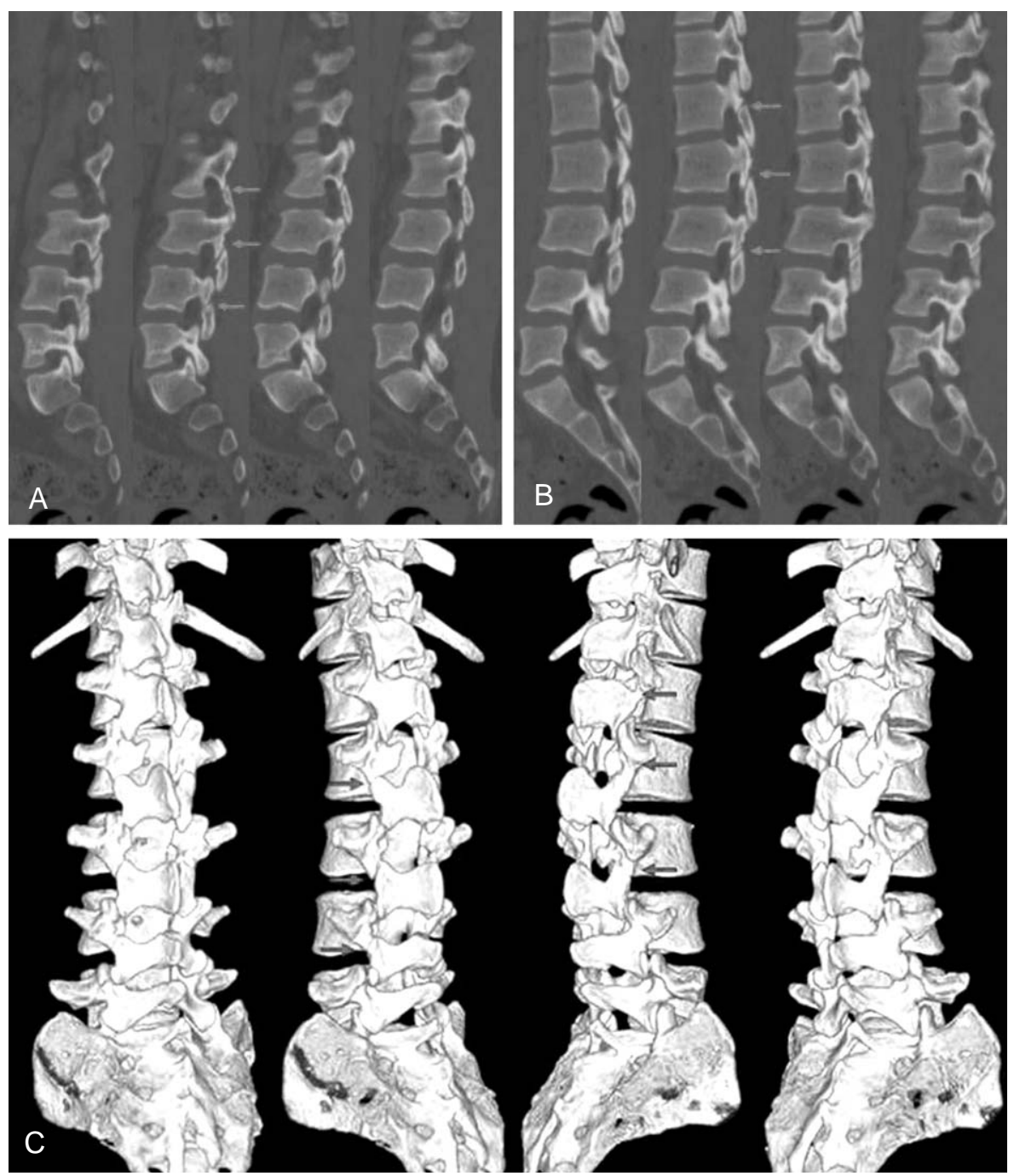

Fig. 3. Reconstruction of CT scan- Lumbar spine. (A) Left L2,3,4 pars interarticularis spondylolysis are noted. (B) Right L1,2,3 pars interarticularis spondylolysis are noted. (C) 3D reconstruction of CT scan- Lumbar spine.
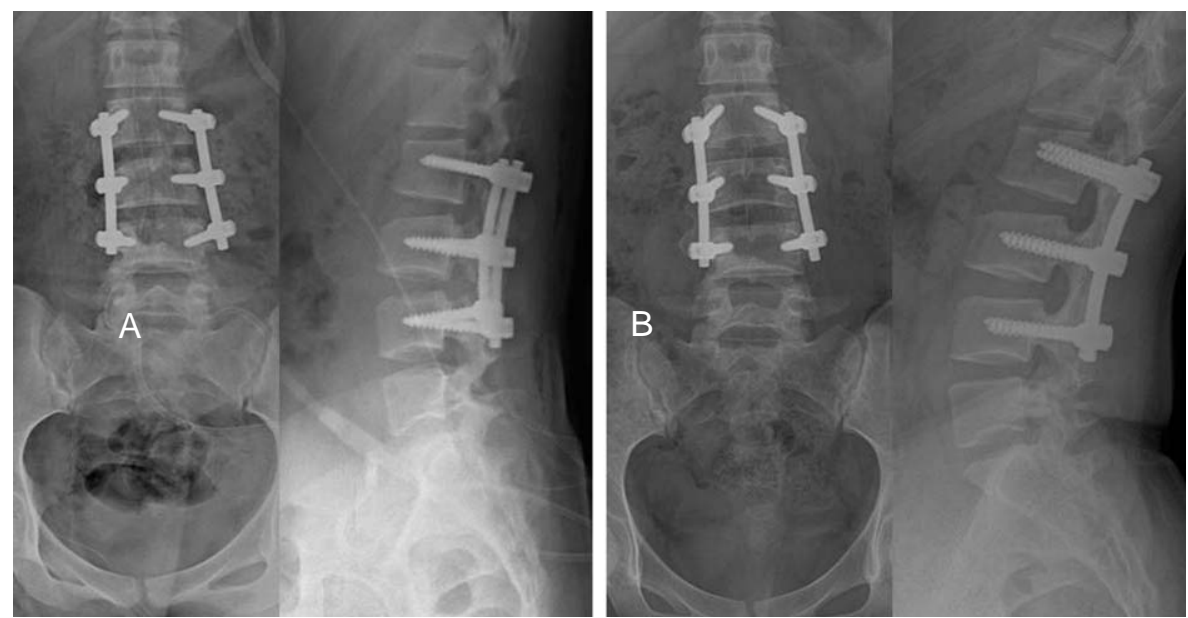

Fig. 4. (A) Immediate postoperative - anteroposterior and lateral radiography of lumbar spine. (B) Postoperative 1 year - anteroposterior and lateral radiography of lumbar spine. There is a successful bony union. 


\section{Discussion}

Lumbar spondylolysis is common at the fourth and fifth lumbar vertebrae. The frequency of spondylolysis in the upper lumbar vertebrae has been estimated by various authors to be between $0.2 \%$ and $1.5 \%$. Two factors play a determinant role in the pathogenesis of spondylolysis: the genetic factor and the mechanical factor of the lumbar spine. Familial occurrence of spondylolysis has been demonstrated by Friberg ${ }^{7}$ and Willis ${ }^{8}$ and Wiltse ${ }^{9}$, and it supports that a genetic factor can be involved with this malady, but the specific gene that affects spondylolysis is unknown. The spondylolysis is not present in embryos, the fetus or at birth and it usually appears as soon as the child begins to stand and walk . Pfeil $^{10}$ found 17 cases of spondylolisthesis and spondylolysis among 500 children. In the report by Wiltse, the youngest patient with spondylolysis was eight and a half months. It is thought that spondylolysis is associated with the upright position. There may be a relation between repetitive trauma and spondylolysis. People employed in heavy industry and people who participate in contact sports seem to be particularly vulnerable to this condition $^{11,12}$. So, multiple spondylolysis is more commonly seen among men. In our case, the patient's symptoms were aggravated after a routine exercise program. We consider that the mechanical factor of the lumbar spine affects a development of spondylolysis for people who are vulnerable due to a genetic factor. In a study of lumbar spondylolysis among 1598 subjects, only two were found to have lesions in the upper three lumbar vertebrae ${ }^{13}$. Furthermore, multi-level spondylolysis at the upper lumbar vertebra is even rarer, and in these case reports, a diagnosis of multiple spondylolysis was made according to the plain radiography ${ }^{14}$. Various radiological modalities like plain radiography, CT and MRI are useful for diagnosing spondylolysis. On the plain radiography, the dynamic flexion-extension views are very useful for assessing the vertebral stability. Three-dimensional (3D) CT reconstruction has greatly increased the reliability and value of a CT examination ${ }^{15}$. In our case, we could confirm the levels of lumbar spondylolysis by using three dimensional CT. We consider that three dimensional CT is a very good and useful tool for the diagnosis of multiple spondylolysis and for making the decision on what level to fuse. In our case, because the patient had constant severe lower back pain for a long time and a spinal deformity and severe instability had developed, the patient underwent a single stage posterolateral fusion and instrumentation. After the operation, the patient was free from her pain and spinal instability. We report here on a well-treated case of multiple spondylolysis.

\section{REFERENCES}

1. Saraste H: Spondylolysis and spondylolisthesis. Acta Orthop Scand Suppl 1993; 251: 84-86.

2. Eisenstein S: Spondylolysis: a skeletal investigation of two population groups. J Bone Joint Surg Br 1978; 60: 488494.

3. Nathan H: Spondylolysis: its anatomy and mechanism of development. J Bone Joint Surg Am 1959; 41: 303-320.

4. Stewart TD: The age incidence of neural-arch defects in Alaskan natives, considered from the standpoint of etiology. J Bone Joint Surg Am 1953; 35: 937-950.

5. Al-Sebai MW, Al-Khawashki H: Spondyloptosis and multiple-level spondylolysis. Eur Spine J 1999; 8: 75-77.

6. Ravichandran G: Upper lumbar spondylolysis. Int Orthop 1981; 5: 31-35.

7. Friberg S: Studies on spondylolisthesis. Acta Chir Scand 1939; 55 Suppl: 1-140.

8. Willis TA: The separate neural arch. J Bone Joint Surg 1931; 13: 709-721.

9. Wiltse LL: Etiology of spondylolisthesis. Clin Orthop 1957; 10: 48-60.

10. Pfeil E: Spondylolysis and spondylolisthesis in children. Z Orthop Ihre Grenzgeb 1971; 109: 17-33.

11. Raynal L, Collard M, Elbanna S: Traumatic spondylolysis: analysis of 4,619 cases of lumbosacral spine. Acta Orthop Belg 1977; 43: 653-659.

12. Wiltse LL, Widell EH Jr, Jackson DW: Fatigue fracture: the basic lesion is inthmic spondylolisthesis. J Bone Joint Surg Am 1975; 57: 17-22.

13. Libson E, Bloom RA, Dinari G: Symptomatic and asymptomatic spondylolysis and spondylolisthesis in young adults. Int Orthop 1982; 6: 259-261.

14. Lowe J, Libson E, Ziv I, et al: Spondylolysis in the upper lumbar spine: a study of 32 patients. J Bone Joint Surg Br 1987; 69: 582-586.

15. Krupski W, Majcher P: Radiological diagnostic of lumbar spondylolysis. Ortop Traumatol Rehabil 2004; 6: 809818. 